\title{
Quyền riêng tư trên thế giới và ở Việt Nam
}

\author{
Nguyễn Đăng Dung ${ }^{*}$, Nguyễn Đăng Duy \\ Khoa Luật, Đại học Quốc gia Hà Nội, 144 Xuân Thủy, Cầu Giấy, Hà Nội, Việt Nam \\ Nhận ngày 16 tháng 8 năm 2017 \\ Chỉnh sửa ngày 18 tháng 9 năm 2017; Chấp nhận đăng ngày 25 tháng 9 năm 2017
}

\begin{abstract}
Tóm tắt: Không được ghi nhận ngay từ đầu, chỉ được suy ra từ quyền bất khả xâm phạm nhà cửa, quyền riêng tư nhanh chóng trở thành quyền con người quan trọng trong hệ thống các quyền con người của một số quốc gia phát triển. Tiếp thu thành quả đó, Liên hợp quốc trang trọng ghi nhận quyền này trong Bộ luật Nhân quyền của mình. Với tư cách là quốc gia thành viên của nhiều Công ước quốc tế về nhân quyền, Việt Nam không chỉ ghi nhận, mà còn tìm nhiều biện pháp khác nhau để bảo vệ quyền này trong một môi trường kinh tế chuyển đổi.
\end{abstract}

Tù khóa: Quyền con người; quyền riêng tư; quyền bất khả xâm phạm nhà ở.

\section{Sự xuất hiện quyền riêng tư và sự phát triển nội hàm của nó từ quyền bất khả xâm phạm nhà ở/nơi cư trú}

Các quyền con người thường được hiểu là không bao giờ tĩnh, và bao giờ cũng thay đổi theo thời gian và theo không gian. Ví dụ quyền tự do ngôn luận có nghĩa là mọi người dân ở hầu hết các vùng ở mọi quốc gia đều có quyền nói, viết ra những gì mà con người suy nghĩ, nhưng với những cách thức thể hiện cách viết và cách nói ra thay đổi theo thời gian và kết quả là trong nhiều trường hợp bản chất của quyền cũng có thể thay đổi. Khi thông qua Hiến pháp thành văn đầu tiên của thế giới cũng gần với thời gian ra đời của các Tuyên ngôn Nhân quyền của Anh và của Pháp người ta không thể tưởng tượng rằng con người có quyền như hiện nay về bí mật đời tư, về bí mật thư điện tử... Nhưng trong suốt chiều dài lịch sử đấu tranh và

\footnotetext{
*Tác giả liên hệ. ĐT.: 84-24-37547913.

Email: dangdung52.pld@gmail.com

https://doi.org/10.25073/2588-1167/vnuls.4115
}

gìn giữ từ khi ra đời cho đến hiện nay ba trong số những quyền tự nhiên: quyền được sống, quyền được tư do và quyền được sở hữu vẫn là nhũng quyền co bản, đặt tiền đề cho viẹc sinh ra các quyền tụ do ngôn luận, quyền bất khả xâm phạm thân thể, quyền bi mật thur tín, bi mật đời tu... Quyền bí mật thư tín được sinh ra từ bất khả xâm phạm nhà cửa, nơi cư trú.

Theo Từ điển tiếng Việt, bí mật đời tư của cá nhân được hiểu là những gì thuộc về đời sống riêng tư của cá nhân (thông tin, tư liệu...) được giữ kín, không công khai, không tiết lộ ra. Nếu các thông tin, tư liệu cá nhân đã được công khai, lộ ra thì không còn là bí mật đời tư nữa. Do đó, cần hiểu bí mật đời tư của cá nhân là những thông tin, tư liệu mà chỉ mỗi cá nhân đó biết và quyêt giữ bí mật. Nếu đó là chuyện diễn ra nơi công cộng, là chuyện mà cá nhân đó đã để lộ ra cho người khác biết thì không còn là bí mật đời tư nữa.

Quyền riêng tư của người Anh được suy diễn từ quyền bất khả xâm phạm nơi cư trú/ nhà ở. Theo Hiến pháp của nước Anh điều quan trọng là con người phải được bảo đảm an toàn 
trong ngôi nhà của chính mình. Ngôi nhà thường được gọi là lâu đài và pháp luật sẽ không cho phép ai, kể cả cảnh sát trưởng bước chân vào, trừ khi có sự cho phép của chủ nhà và trong trường hợp có dấu hiệu phạm tội. Về quyền của người dân được an toàn trong ngôi nhà của mình, William Pitt - một trong những Thủ tướng trẻ và tài năng nhất trong các đời Thủ tướng của nước Anh thế kỷ XVIII đã cho rằng: Người nghèo nhất trong ngôi nhà của mình cũng có thể thách thức mọi lực lượng của Nhà Vua. Mặc dù ngôi nhà đó có thể tạm bợ, mái nhà có thể lung lay, gió có thể thổi vào, bão có thể ập đến, mưa có thể rơi xuống, nhưng Đức Vua của nước Anh không thể xâm nhập, tất cả các lực lượng của Ngài không thể bước qua ngưỡng cửa của căn nhà lụp xụp ấy[1].

Quyền riêng tư được hiểu là quyền của mỗi người được bảo toàn trước mọi sự tọc mạch, bảo đảm mỗi hành động của cá nhân hay là việc riêng không bị phơi bày trước công chúng. Quyền này gắn liền với quyền chống lại những vi phạm quyền riêng tư của mỗi cá nhân. Cho đến tận thế kỷ thứ XVIII, sự riêng tư có ý nghĩa đơn giản là sự cô độc, sự tách biệt, hay khoảng không gian riêng của mỗi con người liên quan đến ngôi nhà của họ. Lúc đó hầu hết mọi người đều sống chung trong một gia đình, cả gia đình ngủ chung trong một căn phòng nhỏ hẹp. Nhưng cùng với phát triển của nhân loại với sự phát triển thịnh vượng của phương Tây, nhiều người ở tầng lớp trung lưu có nhà riêng rộng hơn, và có phòng riêng cho từng người, nên quyền riêng tư được dùng với nghĩa cá nhân. Chuyện riêng của mỗi người không liên quan đến người khác. Quyền riêng tư được hiểu dần dần là quyền cá nhân của mỗi con người. Cho dù là Chính phủ đại diện cho quốc gia cho đến những người dân thường khác không ai có quyền được biết về cuộc sống riêng tư của họ. Thuở ban đầu "sư riêng $t u$ " chỉ được đề cập đến việc nói xấu, chiếm đoạt tên hay hình ảnh của một người khác, mà không được phép của người đó [1].

Đó là tổng hợp tất cả những gì mà người ta những yếu tố chính của quyền riêng tư, quyền được ở an toàn trong ngôi nhà của mình trước mọi thế lực của Chính phủ. Việc luật pháp bảo vệ an toàn cho ngôi nhà chính là việc trước hết bảo vệ quyền con người trong ngôi nhà của họ.

Mối đe dọa lớn nhất đến quyền riêng tư gắn với sự phát triển của báo chí hàng ngày vào cuối thế kỷ XIX. Nhiều tòa soạn cùng với những chủ bút khác nhau của họ đã phát hiện ra rằng, đa số người dân rất mong muốn tìm hiểu đời sống riêng tư của những người giàu, người nổi tiếng và những chính trị gia. Các phương tiện thông tin đại chúng không chỉ công khai những hoạt động, mà còn phơi bày những nhược điểm của họ. Do đó luật bảo vệ quyền riêng tư chủ yếu được ban hành nhằm giải quyết vấn đề danh tiếng và nhân phẩm của con người. Luật này cấm can thiệp vào công việc của người khác, công khai những khía cạnh riêng tư, nhằm mục đích bôi nhọ danh tiếng của con người.

Mặc dù có sự tiếp thu thành quả của nhà nước Anh, nhưng quyền riêng tư là quyền không được đề cập một cách cụ thể và trực tiếp trong Hiến pháp 1787 ở Mỹ quốc. Quyền riêng tư là quyền do Tòa án trao cho các chủ thể qua các quyết định xét xử khi các thẩm phán phải giải thích các Tu chính án thứ ba và thứ tư Hiến pháp Mỹ năm 1791:

Tu chính án Thư ba: Không một quân nào, trong thời bình được đóng quân trong nhà dân nếu không được chủ nhà cho phép, ngay cả trong thời chiến cũng phải theo quy định của pháp luật.

Điều bổ sung này phát sinh trực tiếp từ một vụ kiện chống lại người Anh khi bắt người dân phải nhận binh lính vào ở trong nhà của họ [2].

Tu chinh án Thú tu: Quyền con người được bảo đảm về cá nhân, nhà cửa, giấy tờ và các tài sản khác khỏi mọi sư khám xét, tịch thu và bắt giam vô lý. Không một lệnh, một trát nào được cấp, nếu không có lý do xác đáng, căn cú vào có lời tuyên thệ hoạc xác nhận, đặc biệt cần miêu tả chính xác các địa điểm khám xét, người và đồ vật bắt giũu.

Biện pháp này không ngăn cấm các nhà chức trách pháp lý truy nã, thu giữ hàng hóa hay bắt giữ người. Chỉ yêu cầu đơn giản rằng, 
trong hầu hết các trường hợp các nhà chức trách phải có lệnh truy nã của tòa án khi chứng minh được yêu cầu cần thiết phải có lệnh này. Các bằng chứng có được do vi phạm điều bồ sung này sẽ không được coi là bằng chứng trong phiên tòa xét xử tội phạm [2].

Cho đến tận giữa thế kỷ XIX mọi người dân Mỹ đều cho rằng quyền riêng tư là quyền không được xâm phạm đển nhà riêng của họ. Sau cuộc Nội chiến năm 1861-1864, hàng triệu người di cư vào thành phố, khiến điều kiện sống cùng với nhà ở riêng của họ trở nên rất khó khăn, đông đúc và chật chội, khái niệm và nội hàm quyền riêng tư phải thay đổi. Quyền riêng tư dần dần được hiểu là quyền không được xâm phạm đến đời tư cá nhân của từng con người.

Thời hiện đại khi xuất hiện điện thoại, mạng internet, mạng xã hội, việc xâm phạm đến quyền riêng tư không phải thâm nhập vào nhà của người khác, không cần phải bước chân đến ngôi nhà của người bị xâm hại. Những phát minh công nghệ khác như máy quay phim, máy ghi âm, chụp ảnh đắt tiền cho đến gương phản chiếu rẻ tiền có thể giúp người ta hoàn toàn nhìn thấu người khác, nghe thấy nhiều điều khác và thọc mũi vào chuyện riêng tư của người khác, mà không cần phải trực tiếp đặt chân đến nhà của họ.

Nhiều thẩm phán của Mỹ quốc vào đầu thế kỷ XX nhận thấy sự vô lý khi những người viết Hiến pháp với Điều bổ sung/Tu chính án Thứ tư không sử dụng quyền "riêng tư" một cách cụ thể, như không đề cập đến quyền nghe lén. Nhưng rồi họ cũng hiểu ra rằng, thời đó điện thoại chưa được phát minh ra. Cuối cùng vào những năm 60 của thế kỷ trước, Tòa án đã phán quyết hành vi nghe lén là vi phạm quyền riêng tư được Hiến pháp của họ bảo vệ. Theo lời giải thích của thẩm phán Stewart, Điều bổ sung sửa đổi Thứ tư bảo vệ con người chứ không phải chỉ bảo vệ nhà ở /địa điểm. Nếu người nào có yêu cầu riêng tư chính đáng thì họ có thể viện dẫn đến sự bảo vệ của Hiến pháp [2].

Trong thời đại công nghệ số hóa phát triển mạnh mẽ như hiện nay, việc đưa các thông tin cá nhân của mình lên mạng để sử dụng vào những mục đích khác nhau, đã dần trở nên quen thuộc. Việc làm này một mặt giúp thuận tiện hơn trong việc sử dụng các dịch vụ xã hội, nhưng mặt trái của nó là tồn tại những nguy cơ bị người khác đánh cắp thông tin để thực hiện những hành vi trái pháp luật như giả mạo bạn bè, người thân để lừa đảo, làm giả thẻ ngân hàng... Thực tế đã khuyến cáo mạnh mẽ rằng, công nghệ sẽ tạo thêm quyền lực cho chính quyền. Các cơ quan nhà nước không chỉ có thể nghe lén, các cuộc nói chuyện điện thoại hay các cuộc nói chuyện trực tiếp, mà còn còn có thể lục soát các giấy tờ, tài liệu mà không cần như trước đây phải đột nhập vào nhà riêng của con người [1]. Các bức ảnh chụp lén và tính táo bạo của báo chí đã xâm phạm đến những phần thiêng liêng trong cuộc sống gia đình riêng tư và rất nhiều những dụng cụ máy móc đe dọa những gì được thì thầm trong phòng kín đều sẽ bị công bố trên nóc nhà [3]. ${ }^{1}$

Việc phòng chống hành vi vi phạm quyền riêng tư của người dân không chỉ chủ yếu dừng lại từ phía các chủ thể mang trách nhiệm thực thi công vụ, trước hết là cơ quan, người thực thi công việc nhà nước, mà còn cả các chủ thể khác như người thực thi các dịch vụ công, và kể cả những người khác có khả năng sử dụng các phương tiện truyền thông hiện đại gắn liền với công nghệ thông tin.

Ngày nay không khó để tìm kiếm được trên mạng thông tin cá nhân, những bí mật gia đình, đời sống tình cảm riêng tư của một số chính trị gia, diễn viên, ca sĩ, người mẫu nổi tiếng, thậm chí là những ồn ào xung quanh vụ scandal trong giới showbiz. Chưa bàn tới việc những thông tin này khi đăng tải có được sự cho phép của người trong cuộc hay không, việc công khai những thông tin đó có thể dần đến tổn hại về tinh thần, danh dự, nhân phẩm, uy tín của cá nhân người đó. Chính vì thế, việc biết được những thông tin cá nhân của mình có được pháp luật bảo vệ hay không, phạm vi thông tin cá

\footnotetext{
${ }^{1}$ Samuel D. Warren and Louis Brandeis "Quyền riêng tư" (1890). Trích theo Melvin Urofsky: Các quyền con nguời được Hiến pháp bảo đảm (Individual Freedom and the Bill of Rights) http://vietnam.usembassy. gov tr.82
} 
nhân được bảo vệ như thế nào, mức độ bảo vệ ra sao... là điều hết sức quan trọng và cần thiết. Đây chính là những quy định của pháp luật "quyền về đời sống riêng tư, bí mật cá nhân, bí mật gia đình", một trong những quyền nhân thân cơ bản của cá nhân phải được luật pháp bảo vệ.

Quyền riêng tư cũng như hầu hết các quyền khác liên quan trực tiếp đến dân chủ và phát triển. Mặc dù phải sống thành xã hội tức là loài người có nhu cầu giao tiếp với nhau và họp thành cộng đồng với những sinh hoạt chung, nhưng vẫn không đủ. Bên cạnh những sinh hoạt chung trong cộng đồng, mỗi cá nhân con người vẫn cần phải có nhu cầu về thời gian, không gian cho riêng mình. Chính những yêu cầu khách quan đó tạo nên những quyền riêng tư của họ. Sự riêng tư không phải là sự tách biệt hay sự ly khai, mà nó là mong muốn tự thân của mỗi con người được ở một mình hay ở với một vài người khác. Việc bắt giam một người trong phòng giam của nhà tù không phải là sự riêng tư, nhưng đi dạo một mình trong công viên lại chính xác là sự riêng tư. Quyền riêng tư là quyền của mỗi người, cho tất cả mọi người, mà không phải là quyền của một nhóm người. Nếu không có quyền riêng tư, con người không thể phát triển được ý thức rằng: tính cá nhân của con người là một giá trị thực chất mô tả vai trò mỗi con người trong xã hội. Ngược lại, nếu không có sự ý thức về tính cá nhân, thì sẽ không thể có nhận thức về nhu cầu của sự riêng tư.

Một minh chứng cho sự thay đổi cách hiểu nội hàm quyền riêng tư trong thời đại công nghệ là việc đưa thêm con người có quyền từ chối điều trị y khoa và tìm đến cái chết vào các quyền riêng tư của con người. Tòa án Tối cao Hoa kỳ vào những năm cuối cùng của thế kỷ $\mathrm{XX}$ với một vấn đề hoàn toàn mới không có tiền lệ của quyền riêng tư là yêu cầu được chết. Có những người gặp những căn bệnh, hay tai nạn hiểm nghèo có thể duy trì được sự sống của mình nhờ tiến bộ khoa học công nghệ, nhưng sự sống của họ rất khổ sở, họ quyết định chết còn hơn sống một cách sống với những máy móc $\mathrm{y}$ học phức tạp gắn liền. Tòa án Tối cao Hoa kỳ với Chánh án W. Rechnquist đã cho rằng, Hiến pháp có tinh thần bảo đảm quyền được chết trong những bảo đảm quyền tự quyết của con người trong Điều bổ sung thứ Mười bốn. Trong một vài năm sau đó một loại hình mới của quyền riêng tư là quyền được chết được xác định chính thức trong hệ thống pháp luật của 50 tiểu bang và Liên bang [1].

Cho đến hiện nay người ta vẫn còn tiếp tục tranh cãi về phạm vi khái niệm quyền riêng tư. Trong khi mọi người đều nhất trí với những bệnh nhân đang ở trong giai đoạn cuối được phép từ chối điều trị nếu họ lựa chọn quyền được chết, thì không ít người lại cho rằng khái niệm quyền tự quyết dẫn đến cái chết cần kèm thêm quyền tự chết với sự giúp đỡ của bác sĩ. Nếu ở trường hợp trên được nhiều người đồng tình, thì quan điểm này lại không được nhiều người ủng hộ [1]. Người bác sĩ giúp đỡ người muốn chết trong trường hợp này có phạm tội giết người hay không vẫn chưa có lời giải của pháp luật một cách rõ ràng.

\section{Quyền riêng tư trong công pháp quốc tế}

Mãi cho khoảng gần giữa thế kỷ XX, Luật quốc tế về nhân quyền mới được phát triển, tận dụng những thành quả phát triển luật pháp của các quốc gia phát triển, với tầm quan trọng của mình, quyền riêng tư là một quyền dân sự cơ bản của mọi cá nhân, được Bộ luật Nhân quyền quốc tế bảo vệ không cần thiết có những cuộc tranh luận nào sôi nổi nào giữa các thành viên trong tổ biên tập các văn kiện của Liên hợp quốc. Quyền được bảo vệ đời tư trước hết được đề cập tại Điều 12 Tuyên bố quốc tế về Nhân quyền được Đại hội đồng Liên hợp quốc thông qua ngày 10/12/1948 đã ghi nhận:

"Không ai phải chịu sụ can thiệp một cách tùy tiện vào cuộc sống riêng tu, gia dình, noi ở hoạc thu tín, cũng nhu bị xúc phạm danh dụ hoặc uy tín cá nhân. Mọi người đều có quyền được pháp luật bảo vệ chống lại sụ can thiệp và xâm phạm nhu vây.",

Quyền riêng tư được xem như là một quyền bao trùm bao gồm tất cả các quyền khác nhau 
được đề cập trong Điều 12 của Tuyên ngôn Nhân quyền, nó quan hệ mật thiết với quyền bảo vệ gia đình, nơi ở, nơi cư trú, thư tín, điện thoại, thư điện tử và các phương tiện giao tiếp điện tử khác, cũng như sự toàn vẹn về thể chất và tinh thần. Quyền này phải được đánh giá trong môi trường đó [4]. Quyền được bảo vệ đời tư được tái khẳng định tại Điều 17 Công ước quốc tế về các quyền dân sự và chính trị. Trong đó nêu rằng:

Không ai bị can thiệp một cách tùy tiện hoạc bất hơp pháp vào đời sống riêng tur, gia đình, nhà ở, thu tín, hoặc bị xâm phạm bất hơp pháp đến danh dưv và uy tín.

Mọi người đều có quyền được pháp luật bảo vệ chống lại nhũng can thiệp hoặc xâm phạm nhu vâyy.

Điều 17 quy định quyền được bảo vệ của mọi người nhằm chống lại sự xâm phạm tuỳ tiện hay bất hợp pháp về đời tư, gia đình, quê hương và những người liên quan cũng như chống lại sự xâm hại bất hợp pháp đến danh dự và uy tín của họ. Theo quan điểm của Uỷ ban, cần thiết phải có quyền này để đảm bảo chống lại những xâm phạm như trên, cho dù những sự xâm phạm này là do quan chức nhà nước hay bất kỳ thể nhân và pháp nhân gây ra. Những nhiệm vụ bắt buộc của điều khoản này đòi hỏi các Quốc gia phải thực thi các biện pháp pháp lý và những biện pháp thích hợp khác có tác động ngăn chặn, chống lại sự xâm phạm và tấn công vào đời tư để bảo vệ quyền này [5].

Với sự phát triển của khoa học công nghệ, những hình thức can thiệp tinh vi phát triển một cách đáng kể trong mấy thập niên gần đây, vì thế gia tăng mức độ nguy hiểm của những hành vi xâm phạm quyền riêng tư. Ví dụ việc chính quyền tăng cường biện pháp giám sát điện tử đối với cá nhân con người, hay việc xây dựng hệ thống tư liệu và những ngân hàng dữ liệu cá nhân được vi tính hóa là những cách thức mà phát triển khoa học công nghệ có thể làm phát sinh mối nguy hại cho việc bảo vệ cuộc sống riêng tư của con người [6].

Vì sự an toàn của tất cả mọi người trong xã hội, quyền về sự riêng tư không phải là quyền tuyệt đối. Tuy nhiên, các quốc gia chỉ nên thu thập thông tin về đời tư, nếu như những thông tin đó là thiết yếu để bảo đảm lợi ích chung của xã hội như được thừa nhận trong ICCPR.

Theo quy định ở Điều 17 ICCPR, tính toàn vẹn và bảo mật của thư tín phải được bảo đảm cả về mặt pháp lý và thực tế. Thư từ phải được giao tận tay người nhận mà không bị chặn lại, mở ra hay nói cách khác là xem trước. Việc theo dõi, bất kể bằng biện pháp điện tử hay các biện pháp khác, ví dụ như nghe trộm điện thoại, điện tín... đều bị nghiêm cấm. Việc lục soát nhà cửa phải bị giới hạn chỉ được sử dụng trong trường hợp để tìm chứng cứ cần thiết và không được phép gây phiền nhiễu cho chủ nhà. Việc khám xét thân thể phải theo cách thức phù hợp để bảo đảm nhân phẩm của người bị khám xét; người khám xét phải cùng giới tính với người bị khám xét. Việc thu thập và lưu giữ các thông tin cá nhân trong máy tính, các ngân hàng dữ liệu và các thiết bị khác, cho dù là bởi các quan chức nhà nước hay các thể nhân, pháp nhân khác, đều phải được quy định trong pháp luật. Nhà nước phải có những biện pháp hiệu quả để bảo đảm rằng những thông tin cá nhân đó không rơi vào tay những người không được pháp luật cho phép và không bị sử dụng vào các mục đích trái với Công ước. Để bảo đảm bảo vệ đời tư một cách hiệu quả, mỗi cá nhân cần có quyền được biết liệu thông tin cá nhân của mình có bị thu thập, lưu giữ bởi chủ thể nào không và nếu có, thì ở đâu, nhằm mục đích gì, chủ thể quản lý thông tin cá nhân của mình là ai. Thêm vào đó, mỗi cá nhân cũng cần có quyền yêu cầu sửa chữa hoặc xóa bỏ thông tin cá nhân của mình nếu thông tin đang được lưu trữ không chính xác, hoặc bị thu thập hay lưu trữ một cách trái pháp luật.

\section{Quyền riêng tư trong pháp luật Việt Nam}

Với tính chất quan trọng như đã phân tích ở những điều trên, không phải qua các bước thăng trầm của vấn đề như của các quốc gia phát triển, quyền riêng tư quy định ngay trong đạo luật hiệu lực pháp lý cao nhất - tức là Hiến pháp 
của nước $\mathrm{CHXHCN}$ Việt Nam. Điều 21 và Điều 22 của Hiến pháp này quy định quyền riêng tư với tinh thần rất hiện đại:

1. Mọi người có quyền bất khả xâm phạm về đời sống riêng tu, bi mật cá nhân và bi mật gia đình; có quyền bảo vệ danh dụ, uy tín của mình.

Thông tin về đời sống riêng tur, bi mật cá nhân, bi mật gia đình được pháp luật bảo đảm an toàn.

2. Mọi người có quyền bí mật thu tín, điện thoại, điện tín và các hình thức trao đổi thông tin riêng tu khác.

Không ai được bóc mở, kiểm soát, thu giũ trái luật thu tín, điện thoại, điện tín và các hình thức trao đổi thông tin riêng tư của người khác. (Điều 21)

Tiếp theo Điều 22 quy định:

\section{Công dân có quyền có nơi ở hợp pháp.}

2. Mọi người có quyền bất khả xâm phạm về chồ ở. Không ai được tư ý vào chố ở của người khác nếu không được người đó đồngý.

\section{Việc khám xét chỗ ở do luật định.}

Thể chế hóa các quy định của Hiến pháp, pháp luật dân sự quy định cụ thể "Quyền bí mật đời tư"; "Quyền về đời sống riêng tư, bí mật cá nhân, bí mật gia đình”, Bộ Luật Dân sự năm 2015 quy định về Quyền của cá nhân đối với hình ảnh của mình: Việc sử dụng hình ảnh của cá nhân phải được người đó đồng ý; Việc sử dụng hình ảnh của người khác vì mục đích thương mại thì phải trả thù lao cho người có hình ảnh, trừ trường hợp các bên có thỏa thuận khác.

Pháp luật quy định rõ trong trường hợp sau đây không cần có sự đồng ý của người có hình ảnh hoặc người đại diện theo pháp luật của họ: a) Hình ảnh được sử dụng vì lợi ích quốc gia, dân tộc, lợi ích công cộng; b) Hình ảnh được sử dụng từ các hoạt động công cộng, bao gồm hội nghị, hội thảo, hoạt động thi đấu thể thao, biểu diễn nghệ thuật và hoạt động công công khác mà không làm tổn hại đến danh dự, nhân phẩm, uy tín của người có hình ảnh. Việc sử dụng hình ảnh mà vi phạm quy định tại Điều này thì người có hình ảnh có quyền yêu cầu Tòa án ra quyết định buộc người vi phạm, cơ quan, tổ chức, cá nhân có liên quan phải thu hồi, tiêu hủy, chấm dứt việc sử dụng hình ảnh, bồi thường thiệt hại và áp dụng các biện pháp xử lý khác theo quy định của pháp luật.

Đời sống riêng tư, bí mật cá nhân, bí mật gia đình là bất khả xâm phạm và được pháp luật bảo vệ: Việc thu thập, lưu giữ, sử dụng, công khai thông tin liên quan đến đời sống riêng tư, bí mật cá nhân phải được người đó đồng ý, việc thu thập, lưu giữ, sử dụng, công khai thông tin liên quan đến bí mật gia đình phải được các thành viên gia đình đồng ý, trừ trường hợp luật có quy định khác; Thư tín, điện thoại, điện tín, cơ sở dữ liệu điện tử và các hình thức trao đổi thông tin riêng tư khác của cá nhân được bảo đảm an toàn và bí mật; việc bóc mở, kiểm soát, thu giữ thư tín, điện thoại, điện tín, cơ sở dữ liệu điện tử và các hình thức trao đổi thông tin riêng tư khác của người khác chỉ được thực hiện trong trường hợp luật quy định; Các bên trong hợp đồng không được tiết lộ thông tin về đời sống riêng tư, bí mật cá nhân, bí mật gia đình của nhau mà mình đã biết được trong quá trình xác lập, thực hiện hợp đồng, trừ trường hợp có thỏa thuận khác.

BLDS 2015 đã không tiếp tục sử dụng thuật ngữ "Quyền bí mật đời tư" như quy định tại BLDS 1995 và 2005 mà sử dụng thuật ngữ "Quyền về đời sống riêng tư, bí mật cá nhân, bí mật gia đình". Sự thay đổi này phù hợp với quy định tại Điều 21 và Điều 22 của Hiến pháp 2013 hiện hành. Tuy nhiên, nội dung quy định nói trên vẫn chưa đưa ra được khái niệm về đời sống riêng tư, bí mật cá nhân, bí mật gia đình.

Luật an toàn thông tin mạng được Quốc hội thông qua năm 2015 quy định rõ trách nhiệm của các cơ quan tổ chức và cá nhân trong việc thu thập và sử dụng thông tin cá nhân. Tổ chức, cá nhân xử lý thông tin cá nhân có trách nhiệm sau đây:

a) Tiến hành thu thập thông tin cá nhân sau khi có sự đồng ý của chủ thể thông tin cá nhân về phạm vi, mục đích của việc thu thập và sử dụng thông tin đó; b) Chỉ sử dụng thông tin cá nhân đã thu thập vào mục đích khác mục đích 
ban đầu sau khi có sự đồng ý của chủ thể thông tin cá nhân; c) Không được cung cấp, chia sẻ, phát tán thông tin cá nhân mà mình đã thu thập, tiếp cận, kiểm soát cho bên thứ ba, trừ trường hợp có sự đồng ý của chủ thể thông tin cá nhân đó hoặc theo yêu cầu của cơ quan nhà nước có thẩm quyền.

Cơ quan nhà nước chịu trách nhiệm bảo mật, lưu trữ thông tin cá nhân do mình thu thập. Chủ thể thông tin cá nhân có quyền yêu cầu tổ chức, cá nhân xử lý thông tin cá nhân cung cấp thông tin cá nhân của mình mà tổ chức, cá nhân đó đã thu thập, lưu trữ (Điều 17).

Cá nhân có quyền yêu cầu tổ chức, cá nhân xử lý thông tin cá nhân cập nhật, sửa đổi, hủy bỏ thông tin cá nhân của mình mà tổ chức, cá nhân đó đã thu thập, lưu trữ hoặc ngừng cung cấp thông tin cá nhân của mình cho bên thứ ba. Tồ chức, cá nhân xử lý thông tin cá nhân phải áp dụng biện pháp quản lý, kỹ thuật phù hợp để bảo vệ thông tin cá nhân do mình thu thập, lưu trữ; tuân thủ các tiêu chuẩn, quy chuẩn kỹ thuật về bảo đảm an toàn thông tin mạng. Khi xảy ra hoặc có nguy cơ xảy ra sự cố an toàn thông tin mạng, tổ chức, cá nhân xử lý thông tin cá nhân cần áp dụng biện pháp khắc phục, ngăn chặn trong thời gian sớm nhất.

Xâm phạm bí mật hoặc an toàn thư tín, điện thoại, điện tín của người khác được quy định là tội phạm hình sự. Điều 159 Bộ luật Hình sự quy định tội xâm phạm bí mật hoặc an toàn thư tín, điện thoại, điện tín hoặc hình thức trao đổi thông tin riêng tư khác của người khác:

1. Người nào thực hiện một trong các hành vi sau đây, đã bi xử lý kỷ luật hoặc xủ phạt vi phạm hành chính về hành vi này mà còn vi phạm, thì bị phạt cảnh cáo, phạt tiền tù̀ 20.000.000 đồng đến 50.000.000 đồng hoạc phạt cải tạo không giam giũu đến 03 năm:

a) Chiếm đoạt thu tín, điện báo, telex, fax hoạc văn bản khác của người khác được truyền đưa bằng mạng buu chinh, viến thông dưới bất kỳ hình thức nào;

b) Cố ý làm hu hỏng, thất lạc hoặc cố ý lấy các thông tin, nội dung của thu tín, điện báo, telex, fax hoặc văn bản khác của người khác được truyền đura bằng mang buu chinh, viễn thông; luật;

c) Nghe, ghi âm cuộc đàm thoại trái pháp

d) Khám xét, thu giũ thu tín, điện tín trái pháp luạt;

d) Hành vi khác xâm phạm bi mật hoặc an toàn thu tín, điện thoại, diện tín, telex, fax hoạc hình thức trao đổi thông tin riêng tu khác của người khác.

2. Phạm tội thuộc môt trong các truờng hơp sau đây, thì bị phạt tù tù̀ 01 năm đến 03 năm:

a) Có tổ chức;

b) Lợi dụng chưc vu, quyền hạn;

c) Phạm tọi 02 lần trở lên;

d) Tiết lộ các thông tin đã chiếm đoạt, làm ảnh huơong đến danh dự, uy tín, nhân phẩm của người khác;

d) Làm nạn nhân tụ sát.

3. Người phạm tội còn có thể bị phạt tiền tù̀ 5.000.000 đồng đến 20.000.000 đồng, cấm đảm nhiệm chức vu nhất định tù̀ 01 năm đển 05 năm.

Mặc dù đã có nhiều thay đổi, bổ sung trong quá trình hoàn thiện quy định pháp luật về quyền bí mật đời tư của cá nhân nhưng hiện nay vẫn chưa có một văn bản quy phạm pháp luật nào quy định hoặc hướng dẫn cụ thể, chi tiết như thế nào là "bí mật đời tư" hay "đời sống riêng tư, bí mật cá nhân, bí mật gia đình".

Với ý thức của các chủ thể trong việc tuân thủ các quy định của pháp luật còn chưa cao, hơn nữa quyền riêng tư thuộc vào loại các quyền rất mới với những biểu hiện đa dạng cả ở tầm vĩ mô lẫn vi mô của những hành vi vi phạm, thậm chí còn chứa đựng trong môi trường ảo của công nghệ thông tin, những quy định trên rất khó cho việc thực hiện trên thực tế. Nhiều hành vi vi phạm không được xử lý kịp thời, thậm chí còn chưa được nhận ra. Trong một hệ thống còn ảnh hưởng nặng nề bởi cơ chế tập trung của chủ nghĩa xã hội kiểu cũ, với nguyên tắc chủ nghĩa tập thể, tập trung dân chủ, quyền của con người ít có điều kiện quan tâm, nên quyền riêng tư lại càng có nguy cơ tiềm ẩn 
cho sự vi phạm. Dưới đây là một hiện tượng rất mới nhưng ở Việt Nam vẫn chưa có lời giải đáp một cách thỏa đáng, mà vẫn còn phân vân:

Sau kỳ thi THPT quốc gia năm nay, vấn đề quyền riêng tư đang gây tranh luận trên mạng khi có nhiều ý kiến cho rằng việc công khai điểm thi là vi phạm quyền riêng tư cá nhân. Một số người cho rằng, việc công khai thông tin thí sinh có thể bị lợi dụng để nhục mạ và gây sức ép công khai trên mạng xã hội. Nó cũng có thể được dùng để tạo ra sự cạnh tranh giữa các thí sinh, thúc đẩy một cuộc chạy đua về điểm số, thành tích, giữa học sinh này và học $\sinh$ kia; giữa con của người này với con của người kia. Nhiều trường hợp học sinh bỏ nhà ra đi hoặc tệ hơn là tự tử, do bị tổn thương về tâm lý, vì xấu hổ với bạn bè, thầy cô, hàng xóm vì điểm thi thấp [7].

\section{Kết luận}

Thuở ban đầu của những năm cách mạng tư sản, quyền riêng tư không được ghi nhận trong hệ thống pháp luật của quốc gia, chỉ được thừa nhận sau này từ thực tiễn thông qua các hoạt động xét xử của tòa án và được các thẩm phán luận giải từ quyền bất khả xâm nơi nhà ở của người dân là một quyền con người quan trọng tạo nên sự phát triển của loài người. Tiếp thu các thành quả các nước phát triển như Anh, Mỹ, Pháp, Liên hợp quốc và các quốc gia sau này đều thừa nhận tầm quan trọng của quyền này, và tìm cách bảo vệ trước sự xâm phạm không những từ phía nhà nước, mà còn các chủ thể khác nhau trong thời đại của khoa học công nghệ và thông tin. Là một nhà nước dân chủ đang phát triển, đã ký kết, tham gia nhiều Công ước quốc tế về quyền con người, Việt Nam không những ghi nhận, mà còn tìm mọi biện pháp khác nhau để bảo vệ quyền riêng tư, trong một nền kinh tế đang chuyển đổi.

\section{Tài liệu tham khảo}

[1] Melvin Urofsky: Các quyền con người được Hiến pháp bảo đảm (Individual Freedom and the Bill of Rights) http://vietnam.usembassy. gov

[2] About America the Constitution of USA with Explantory Notes http: // vietnam.usembassy.gov

[3] Samuel D. Warren and Louis Brandeis "Quyền riêng tư” (1890). Trích theo Melvin Urofsky: Các quyền con nguời được Hiến pháp bảo đảm (Individual Freedom and the Bill of Rights http://vietnam.usembassy. gov tr.82

[4] Tuyên ngôn Nhân quyền quốc tế 1948 mục tiêu chung của nhân loại do Gudmundur và Asjorn Eide Chủ biên Nxb. Lao động Xã hội 2011.

[5] Bình luận chung số 16 của Ủy ban Nhân quyền. Trong Giới thiệu Công ước quốc tế về các quyền dân sự và chính trị. $\mathrm{Nxb}$. Hồng Đức 2012, tr.255-260.

[6] Tuyên ngôn Nhân quyền quốc tế 1948 mục tiêu chung của nhân loại do Gudmundur và Asjorn Eide Chủ biên Nxb. Thanh niên, 2017, tr. 261

[7] Tranh luận về công khai điểm thi THPT quốc gia xâm phạm quyền riêng tư. Zing.vn 08/07/2017. 


\title{
Right to Privacy in the World and in Vietnam
}

\author{
Nguyen Dang Dzung, Nguyen Dang Duy \\ VNU School of Law, 144 Xuan Thuy, Cau Giay, Hanoi, Vietnam
}

\begin{abstract}
Being inferred from the concept of "inviolability of domicile", right to privacy has rapidly become an important human right in the human rights system of developed countries. With this achievement, the United Nations solemnly recognizes this right in the International Bill of Human Rights. As a member State of many international conventions on human rights, Vietnam not only recognizes this right, but also has various means for protecting it in a transition economy environment.

Keywords: Human rights, right to privacy, inviolability of domicile.
\end{abstract}

